\title{
O papel da auditoria externa no combate à sonegação
}

The role of external audit in the fight against tax evasion

\author{
1 Renan Gomes de Moura renangmoura@gmail.com \\ 2 Paloma de Lavor Lopes \\ 3 Sandi Siqueira Louzada Amum Faria \\ 1 Universidade do Grande Rio. \\ 2 Centro Universitário Geraldo Di Biase, UGB / Faculdade Sul Fluminense, FaSF. \\ 3 Centro Universitário Geraldo Di Biase, UGB.
}

\section{Resumo}

Na atualidade, com o alto nível de sonegação no Brasil, o governo federal, juntamente com a Receita Federal, vem elaborando métodos informatizados de obrigações acessórias a serem entregues, a fim de se evitar a prática de sonegação. Esses métodos têm o objetivo de mostrar a situação da empresa em um todo, pois, por meio dela, podemos ter clareza nas operações de entradas e saídas de uma empresa. Com a entrega dessas obrigações, as empresas passam por uma auditoria externa mensal, sem necessidade de que os fiscais tenham em mãos as documentações fiscais em papel, já que todas essas informações podem ser baixadas para uma melhor análise. Através de pesquisas bibliográficas, este artigo registra a história da auditoria externa, na qual poderemos identificar os métodos de auditoria que possibilitam verificar se uma empresa que está praticando a sonegação. Esta pesquisa tem por objetivo geral ressaltar a utilização da auditoria externa como uma ferramenta de combate à sonegação. A fim de enriquecimento para a pesquisa realizada, foram feitas duas entrevistas com auditores fiscais, com esclarecimentos dos tópicos abordados no decorrer deste artigo e, como resultado, pode-se entender mais sobre a importância da auditoria externa e de seus meios que objetivam minimizar a prática da sonegação no Brasil.

\section{Palavras-chave}

Auditoria Externa; sonegação; Sintegra; Sped Fiscal; ICMS.

\begin{abstract}
Nowadays, with the high level of tax evasion in Brazil, the federal Government, along with the IRS, has been developing computerized methods ancillary obligations to be delivered, in order to avoid the practice of tax evasion. These methods were designed to show the situation of the company in a whole, because, through it, we can have clarity in operations of inputs and outputs of a company. With the delivery of these obligations, the companies undergo an external audit monthly, without need for the tax have in hand the tax documentation on paper, since all this information can be downloaded to a better analysis. Through bibliographical research, this article records the history of external audit, in which we can identify the audit methods that make it possible to check whether a company is practicing tax evasion. This research aims to highlight the general use of the external audit as a tool to combat tax evasion. The end of enrichment for the survey, two interviews with tax auditors with clarification of topics covered throughout this article and, as a result, one can understand more about the importance of the external audit and of its means that aim to minimize the practice of tax evasion in Brazil.
\end{abstract}

\section{Keywords}

External Audit; tax evasion; Sintegra; Sped Fiscal; ICMS.

\section{Como você deve citar?}

MOURA, Renan Gomes de; LOPES, Paloma de Lavor; FARIA, Sandi Siqueira Louzada Amum. O papel da auditoria externa no combate à sonegação. Cadernos UniFOA, Volta Redonda, n. 31, p. 75-86, ago. 2016. 


\section{INTRODUÇÃO}

No Brasil, existe um grande número de casos de sonegação, como aponta um estudo divulgado pelo Instituto Brasileiro de Planejamento Tributário (IBPT) e, com isso, a receita federal, por meio de métodos informatizados, vem elaborando meios de fecharem o "cerco", para que se evite a prática de sonegar. Essas informações entregues à receita é um meio de auditoria externa à empresa, sem mesmo que haja um contato físico com as documentações.

A auditoria externa tem como objetivo analisar a situação da empresa em todos os aspectos e, com isso, ter um olhar abrangente da situação financeira econômica, incluindo suas despesas e receitas e, no caso das documentações entregues através do Sped Fiscal, confrontar as entradas, as saídas, os cupons fiscais, o Imposto sobre Circulação de Mercadorias e Serviços (ICMS) a recolher, confrontando débitos, créditos e outros aspectos relevantes para se evitar a sonegação. Com isso, questiona-se: qual a importância da auditoria externa, quando tratamos de sonegação?

Esta pesquisa tem por objetivo geral ressaltar a utilização da auditoria externa como uma ferramenta de combate à sonegação. Como objetivos específicos têm-se: relatar a história da auditoria, seu surgimento e evolução; destacar a importância de meios para se evitar a sonegação; e demonstrar quais os meios utilizados pela Receita Federal para auditar empresas.

No princípio, a auditoria surgiu com o objetivo de analisar as verificações de registro e as informações contábeis, com o intuito de verificar a veracidade dos fatos. Seu papel principal consiste em examinar minuciosamente todos os documentos que circulam dentro da empresa e, com isso, fundamentar conclusões expressas através de relatórios. Segundo Attie (2011), "todo trabalho e esforço do auditor estará centrado, por consequência, nos fatores que influenciam tais demonstrações e que acabam desaguando no setor contábil, que é o responsável pelo seu preparo".

Segundo Pinheiro e Cunha (2003, p. 38), a fraude nos meios empresariais "caracteriza-se pela ação intencional e com dolo, praticada por agentes internos ou externos à entidade, de forma não autorizada, com vistas a atentar contra os ativos empresariais, suprimindo desses resultados empresariais". Esse fenômeno tem sido mensurado através de diversas pesquisas que constatam que a soma das perdas atinge número considerável, tanto nos países anglo-saxões, quanto em países latinos.

E, por motivos consideráveis, como a fraude e os erros, é que o auditor precisa de um grande auxilio de relatórios e documentos que necessitam de cuidados especiais, para que os erros na contabilidade e as fraudes não se tornem vícios contínuos na empresa.

\section{AUDITORIA}

No princípio, a auditoria surgiu com o objetivo de analisar as verificações de registro e as informações contábeis, com o intuito de verificar a veracidade dos fatos.

Segundo Crepaldi (2002, p.23), "pode-se definir auditoria como o levantamento, estudo e avaliação sistemática das transações, procedimentos, operações, rotinas e das demonstrações financeiras de uma entidade". 0 autor registra que 
apesar de formalmente organizada em 26 de março de 1957, quando formado o Instituto dos Contadores Públicos do Brasil, em São Paulo, a auditoria foi oficialmente reconhecida apenas em 1968, por ato do Banco Central do Brasil. O fortalecimento da atividade, todavia, ocorreu em 1972 por regulamentação do Banco Central do Brasil, do Conselho Federal de Contabilidade e pela formação de um órgão nacional para a congregação e autodisciplinação dos profissionais, o Instituto dos Auditores Independentes do Brasil (CREPALDI, 2009, p. 185).

A auditoria externa ou auditoria independente teve seu surgimento na evolução do sistema capitalista. No começo, todas as entidades eram fechadas e a maioria era de grupos familiares. Porém, com o passar dos anos, o mercado foi aumentando e houve, então, o acirramento da concorrência, fazendo assim com que as empresas mais antigas começassem a ter uma visão diferente, sobre a qual se sentiu a necessidade de aumentar suas instalações fabris e também administrativas, além de investir na tecnologia e melhorar o desenvolvimento interno no geral, fazendo, assim, uma redução no custo da empresa e tornando seus produtos e serviços mais competitivos no mercado.

Segundo Almeida (2012), para processar todas essas mudanças seria necessário um volume de recursos impossíveis de ser obtido por meios lucrativos da empresa ou dos bens dos seus proprietários e, por isso, as empresas tiveram que recorrer a capitais de terceiros, empréstimos bancários em longo prazo, emissão de debêntures, abrindo seu capital social para novos acionistas. Dessa forma, grande parte das empresas passou a ser não só mais de grupos familiares.

0 autor ainda afirma que, com essas mudanças, os futuros investidores precisavam estar a par da situação econômica financeira da empresa, tais como, o caixa, o patrimônio líquido e como a sua administração financeira estava sendo efetuada. Essa necessidade de informação era para que o novo acionista pudesse avaliar a segurança, a liquidez e a rentabilidade do seu possível investimento e, claro, para verificar possíveis riscos de perda. E a melhor forma de se obter essas informações era por meio das demonstrações de resultado do exercício, do balanço patrimonial, da demonstração das mutações do patrimônio líquido, da demonstração dos fluxos de caixa e das notas explicativas (ALMEIDA, 2012)

Com o surgimento da globalização e expansão dos mercados, resultando no acirramento da concorrência, as empresas tiveram que investir em tecnologia e aprimorar os controles e procedimentos internos, com o interesse de reduzir custos e tornar seus negócios mais competitivos (STIGLITZ, 2007). Entretanto, a necessidade de capitais para investimentos tornou necessária a captação de recursos de terceiros.

Para que terceiros disponibilizassem esses recursos, exigia-se que as demonstrações financeiras da entidade fossem analisadas por profissionais que não tivessem ligação com a empresa, ou seja, alguém independente. Surgiu, então, a profissão do auditor, profissional responsável em analisar as contas e emitir uma opinião.

A causa da evolução da auditoria foi a do desenvolvimento econômico dos países, do crescimento das empresas e expansão das atividades produtoras, gerando crescente complexidade na administração dos negócios e de práticas financeiras. Segundo Attie (2011), no Brasil, o surgimento do mercado de auditoria está relacionado com influências específicas, entre as quais:

- A instalação de filiais e subsidiarias de firmas estrangeiras;

- Necessidades de financiamentos de empresas brasileiras através de entidades internacionais;

- Crescimento dos negócios (necessidade de capital de giro e investimentos fixos), descentralização e diversificação de atividades econômicas;

- Evolução do mercado de capitais; 
- Criação das normas de auditoria para instituições financeiras, determinadas pelo Banco Central do Brasil;

- Criação da CVM - Comissão de Valores Mobiliários;

- Promulgação da Lei das Sociedades Anônimas (Lei 6.404), em 1976.

Segundo Almeida (2012), os órgãos relacionados com a auditoria são: CVM - Comissão de Valores Mobiliários; Ibracon - Instituto Brasileiro de Contadores; CFC e CRC - Conselho Federal de Contabilidade e Conselho Regional de Contabilidade; e Audibra - Instituto dos Auditores Internos do Brasil.

\title{
3 SONEGAÇÃO
}

Segundo Martins (1994, p. 402) "esta modalidade de crime constitui, na legislação penal, crime tributário. Situa-se, portanto, no Direito Penal. 0 fato punível - a sonegação - é contrário à ordem jurídica pela culpabilidade - má intenção do agente, culpa lesiva em seu sentido mais amplo."

O autor explica culpabilidade e má intenção, pois o ato de sonegador está atrelado ao comportamento consciente das organizações que compactuam com as possíveis alterações que farão nos documentos fiscais. Alguns exemplos de sonegação são:

Meia nota: Meio em que não se espelha a verdade na emissão da nota fiscal (com todos os itens vendidos), isto é, propositadamente, são omitidos itens, quantidades e valores com intuito de também reduzir a receita em que, se provada tal situação, caracteriza/materializa o crime classificado "como de resultado", porque se deu o prejuízo material ao Erário pela subtração do imposto.

\begin{abstract}
Têm a intenção de omitir ou reduzir receitas, fraudando com isso o ICMS, IR, e, indiretamente, PIS, COFINS, IPI, ISS, e CS. A legislação regente da matéria fiscal atinentes aos crimes tributários ou de sonegação fiscal apontam para o efetivo exaurimento do processo na via administrativa, com ampla defesa do sujeito passivo e com a possibilidade de se ver livre do crime se pagar o imposto antes da denúncia-crime pelo MP, depois de esgotados todos os recursos no órgão que administra o tributo - que ditará ou não a constituição definitiva do crédito tributário de tal natureza, donde se conclui que a quitação do imposto, antes da denúncia, é uma excludente da criminalidade fiscal, que acarreta o final da lide nos dois âmbitos, penal e administrativo. (SOUZA, 2009).
\end{abstract}

"Notas fiscais calçadas": Os documentos fiscais, geralmente, são emitidos simultaneamente com as mesmas indicações em várias vias, sendo a destinação das mesmas definidas pela legislação tributária. A nota fiscal será considerada "calçada" quando consignar indicações diferentes nas suas vias, por exemplo, quando o contribuinte indicar, na via da nota fiscal que servirá de base para a sua escrituração fiscal, um valor de ICMS devido na operação menor do que aquele indicado na via que acompanha as mercadorias em trânsito. Isso provocará a redução ilícita do tributo devido, caracterizando infração tributária de natureza material qualificada. Lembramos ainda que a emissão de nota fiscal "calçada" é conduta tipificada também como crime contra a ordem tributária, pela inserção de elementos inexatos em documento fiscal, sujeitando-se o infrator à pena de dois a cinco anos de reclusão.

Uma origem para o termo "calçada" seria o uso de um "calço" (pedaço de madeira) entre as vias da nota fiscal, garantindo que o valor preenchido manualmente numa via não ficasse marcado na via seguinte, possibilitando a sonegação do tributo. (CAMARGO, 2008).

Emissão de notas fiscais falsas: Ato de emitir notas fiscais falsas. Segundo o Artigo 298, da Lei $8.137 / 1990$, seria "falsificar, no todo ou em parte, documento particular ou alterar documento particular verdadeiro". A pena correspondente é a reclusão de um a cinco anos e multa. 
Em relação ao Código Penal, enquanto crime de falsidade ideológica, emite-se um documento fiscal, partindo-se de um impresso autêntico, no crime de falsificação de nota fiscal, já que o impresso também é falso. É o caso de emissão de nota fiscal com utilização de talonário confeccionado em duplicidade (talão paralelo - idêntico a outro do mesmo estabelecimento, com o mesmo modelo, série e numeração). É também o caso do talonário que traz como emitente uma empresa fictícia.

Utilização de documentos falsos: Segundo o Artigo 304, seria "fazer uso de qualquer dos papéis falsificados ou alterados, a que se referem os artigos 297 a 302", na Lei $8.137 / 1990$. A pena correspondente à cominada à falsificação ou à alteração."

Em relação ao Código Penal, se o contribuinte se utilizar de nota fiscal emitida com dados falsos ou com base em impresso que não foi confeccionado da forma exigida pela legislação, que seja para acompanhar o transporte da mercadoria ou para documentar a sua compra, estará cometendo o crime previsto para a falsificação ou para a alteração.

Em qualquer das situações acima exemplificadas, não somente os empresários, mas também o profissional contábil responsável pela empresa está sujeito às penalidades, desde que tenha conhecimento e/ou participação do ato doloso.

Esses profissionais, dentro do âmbito de sua atuação e no que se referir à parte técnica, serão responsabilizados juntamente com os contribuintes por qualquer falsidade dos documentos que assinarem e pelas irregularidades de escrituração praticadas no sentido de fraudar o imposto. (Decreto Lei $n^{\circ} 5.844 / 43$, art.39, parágrafo $1^{\circ}$ ).

\subsection{Sonegação e suas consequências}

Para Mello (2010), a sonegação é um problema de muitos países, porém, no Brasil, já se tornou algo enraizado por diversas empresas e também por pessoa física. Isso se deve ao hábito de querer pagar menos impostos ao governo, seja por uma compra de um imóvel, seja pelas vendas de mercadorias ou até ao declarar o Imposto de Renda Pessoa Física (IRPF).

Segundo um estudo divulgado pelo Instituto Brasileiro de Planejamento Tributário (IBTP) "o faturamento não declarado em 2008 totaliza R\$ 1,32 trilhão, correspondendo a 25,05\% do faturamento total das empresas brasileiras" (IBTP, 2009, p.6)

De acordo com os dados divulgados pelo IBTP, $65 \%$ das empresas de pequeno porte praticam a sonegação e, muitas vezes, seu meio de divulgação não é tão abrangente, fazendo assim com que a empresa não se destaque entre as "maiores". Exemplos disso são lojas de bairro, conhecidas só ali na cidade e, no máximo, na região. Então, essa falta de divulgação acaba deixando essas pequenas empresas "fora da reta da fiscalização", mesmo sendo legalizadas. Ainda segundo o IBTP, $49 \%$ das empresas de médio porte praticam sonegação, participando com uma porcentagem menor devido à exposição, e a sonegação, caso feita, além da multa e o risco de serem presos os autores, denigre a imagem da empresa no mercado, pois o mesmo marketing que a divulga é o primeiro que fará com que ela apareça mais, caso ocorra esse escândalo chamado sonegação.

No ranking, as que menos se denigrem são as empresas de grande porte com $27 \%$ da participação, índice menor devido a diversos fatores, como a quantidade de anos exposta no mercado, zelo pelo nome, entre outros. Observando as possíveis irregularidades que uma empresa pode fazer em uma documentação, notamos que atitudes simples, como citado por Souza (2009), podem acarretar diversos problemas futuros com a Receita Federal, que aos poucos vem implantando sistemas que 
dificultam a sonegação, uma forma de auditar a empresa sem que haja a presença de um auditor. Um exemplo claro disso é o Sintegra.

O SINTEGRA consiste num conjunto de procedimentos administrativos e de sistemas computacionais de apoio que está sendo adotado simultaneamente pelas Administrações Tributárias de todas as Unidades da Federação. Do lado dos contribuintes, o propósito é o de simplificar e homogeneizar as obrigações de fornecimento de informações relativas às operações de compra, venda e prestação de serviços interestaduais. Do lado dos fiscos estaduais, o objetivo é o de propiciar maior agilidade e confiabilidade ao tratamento das informações recebidas dos contribuintes e à troca de dados entre as diversas UFs. De acordo com o estabelecido pelo Convênio Confaz 57/95 e alterações posteriores, os contribuintes usuários de Processamento Eletrônico de Dados estão obrigados a fornecer às Administrações Tributárias dos Estados, em meio magnético. Validado, arquivo magnético contendo os dados relativos à totalidade das operações (compra e venda, aquisições e prestações) internas e interestaduais que tenham praticado. (SEFAZ-ES, 2016).

A Resolução Sefaz-RJ 594/2013, em seu artigo $2^{\circ}$, afırma que:

A inclusão das informações dos tipos de registro '54 - item da Nota Fiscal' - e '75 - código de produto ou serviço' - nos arquivos de operações do SINTEGRA, previstos no Manual de Orientação anexo ao Convênio ICMS n. ${ }^{\circ}$ $57 / 95$, passa a ser obrigatória para as operações ocorridas a partir do mês de referência 02/2013.

Essas novas implantações fazem com que todo mês a empresa passe por uma auditoria externa informatizada. Outra maneira que a Receita tem para fiscalizar as empresas é através do Sped Fiscal. Com todas essas obrigações fiscais, as empresas estão, a cada dia, se conceituando e evitando a fraude, já que têm todas as informações à disposição, de forma que haja uma conscientização da importância de se evitar a sonegação.

\subsection{Conceituando fraude}

Cunha e Edgard (2003, p.80-81) conceituam "fraude como qualquer meio usado por uma pessoa com a finalidade de obter uma vantagem injusta sobre outra pessoa, seja por ato ou omissão, por meio de conduta intencional ou má-fé". Dessa forma, constitui-se "fraude tanto fazer quanto omitir algo, podendo essa conduta ser intencional, não necessariamente com o intuito de prejudicar alguém ou de má-fé, onde a intenção é dolosa ou criminosa".

Segundo Crepaldi (2009) "o termo fraude aplica-se a ato intencional de omissão ou manipulação de transações, adulterar documentos, registros e documentações contábeis. A fraude pode ser caracterizada por apropriação indébita de ativos, aplicação de práticas contábeis indevidas". E por fortes motivos, como fraude e erros, o auditor necessita de auxílio de relatórios e documentos analisados cuidadosamente, para que os erros na contabilidade e as fraudes não se tornem vícios contínuos na empresa.

\section{METODOLOGIA}

Neste trabalho, a metodologia empregada consistiu na revisão bibliográfica atrelada à pesquisa de campo com auditores. Sendo assim, o presente trabalho tem o caráter de pesquisa qualitativa. 0 método de coleta utilizado consistiu em entrevistas e o instrumento de coleta embasou-se na realização de um roteiro de entrevista semiestruturado. Ressaltaremos também, os índices de sonegação do Brasil apurados pelo Instituto Brasileiro de Planejamento Tributário (IBPT).

Como evidenciado anteriormente, somada a essa revisão, foram feitas entrevistas com dois auditores, a fim de elucidar as técnicas utilizadas para se evitar a sonegação. Para isso, usou-se como instrumento de coleta um roteiro semiestruturado e os dados produzidos foram tratados a partir de análise de conteúdo. Utilizamos a metodologia de análise de conteúdo, passando pelas três fases de 
Bardin (1977): a pré-análise; a exploração do material; e o tratamento dos resultados, a inferência e a interpretação.

\section{ENTREVISTA COM AUDITORES FISCAIS}

A seguir, relatamos a entrevista realizada com os dois auditores fiscais. Iniciamos o processo, solicitando que os auditores relatassem a sua experiência como auditor externo.

Trabalho com fiscalização externa de ICMS há três anos e meio, em inspetorias regionais de fiscalização. Ao contrário do que ocorreria numa inspetoria de fiscalização especializada, isso faz com que eu trabalhe com todo tipo de sujeito passivo. A legislação tributária é muito complexa e o ICMS é um imposto muito diversificado, exige continuo estudo (AUDITOR 1).

O trabalho de Auditor Fiscal é muito dinâmico, podendo atuar em diversas áreas. Estou há cerca de um ano e meio trabalhando neste cargo e já vivenciei diversas frentes de trabalho. São vários tipos de fiscalizações, cada uma com suas peculiaridades, sendo muito importante conhecer as legislações específicas para se poder atuar de forma correta. Na prática, conversando com os auditores mais antigos, pode-se dizer que para um profissional dessa área ficar experiente no cargo, mais maduro e com maior conhecimento procedimental, seria necessário de 3 a 5 anos em efetiva atividade. Se fosse resumir o trabalho de auditor em uma única palavra, essa seria "dinâmica" (AUDITOR 2).

Observando os auditores, percebemos que ambos possuem experiência na área do ICMS, vivenciando diversos tipos de fiscalizações que exigem estudo contínuo para poder se atuar de forma correta. Ao serem questionados sobre a importância de um auditor externo e de sua função, as respostas foram:

A legislação tributária obriga o sujeito passivo a efetuar o registro de suas operações, efetuar o cálculo da apuração do ICMS e realizar o recolhimento, mas a correção dessas ações depende muito da vontade do sujeito passivo em realizá-las corretamente. Daí a principal função do fiscal externo é promover sobre os sujeitos passivos a percepção de riscos de sofrer sanções pelo descumprimento da legislação tributária. (AUDITOR 1)

A população, em princípio, desconhece o trabalho de Auditor. Posso falar com toda segurança que o trabalho de Auditor é de extrema importância para a sociedade e para o Estado. Ora, se não houvesse a arrecadação proporcionada, em tese, pelos Auditores Fiscais, não haveria como proporcionar os outros serviços consumidos pela população, como, por exemplo, os serviços de saúde, educação e segurança pública, tão tratados pela mídia. É uma carreira de Estado, básica para o bom funcionamento da máquina pública e intimamente ligada aos outros serviços de Estado que a população conhece melhor. (AUDITOR 2)

Os auditores, ao responder sobre essa questão, nos dizem que o auditor externo é de extrema importância para a sociedade, visto que sua principal função é promover, "abrir os olhos" dos riscos ao descumprirem a legislação. Questionamos sobre a importância das obrigações acessórias que são entregues mensalmente (SPED e Sintegra) e as respostas foram:

Para o ICMS, é essencial que haja adequada escrituração contábil das operações de entrada e saída realizadas pelo sujeito passivo da obrigação tributária. Por isso a legislação tributária obriga o sujeito passivo a realizar o registro cuidadoso das informações essenciais dessas operações (sempre acobertada por documento fiscal) em livros fiscais próprios, além do registro do cálculo de operação do imposto de cada período. As obrigações acessórias de entrega periódica (mensal e anual) contêm informações sobre as atividades do sujeito passivo, permitindo ao fisco o controle e monitoramento da arrecadação, além de servirem juridicamente como instrumento de confissão de débitos. (AUDITOR 1)

O Sped é a escrituração fiscal eletrônica: em vez de livros impressos, o sujeito passivo escritura os registros contábeis em arquivos eletrônicos validados por assinatura digital. Sua importância é primordial, visto que são escriturações fiscais em si mesmas. Atualmente, um número relativamente pequeno de empresas - geralmente as maiores - está obrigada à escrituração digital. Esse número aumentará aos poucos, de modo que a partir de 2016 praticamente não mais existirão livros fiscais de papel. (AUDITOR 1) 
O Sintegra é o arquivo que contém, segundo uma organização definida da legislação, o resumo das operações de entradas e saídas. É obrigatório, caso seja utilizado algum sistema eletrônico de processamento de dados para a emissão de documentos fiscais ou impressão e livros fiscais. Muitos de seus registros são redundantes com o Sped e deixarão de ser obrigatórios no futuro. Atualmente é um registro que permite o controle das atividades de um número muito maior de sujeito passivo que o Sped. (AUDITOR 1)

Também há outras declarações periódicas obrigatórias. A mais importante é a GIA ICMS, que é um resumo do cálculo da apuração do ICMS (registrado no livro registro apuração do ICMS) e que tem validade jurídica de confissão de débito, para os valores declarados como devidos como o ICMS ou ICMS FECP. Além do GIA ICMS, há a DECLAN-IPM, que serve para o cálculo da repartição constitucional de $25 \%$ das receitas de ICMS para os municípios em que ocorreram os fatos geradores, e a entrega dos arquivos MFD (Memória Fita Detalhe) dos aparelhos ECF- Emissor de Cupom Fiscal - do sujeito passivo (AUDITOR 1).

Toda forma de controle, para o Estado, é de suma importância. Os casos do Sped e do Sintegra não são diferentes. $\mathrm{Na}$ era digital, trabalhar com recursos desse meio facilita e muito o trabalho dos Auditores. Imaginem, em pleno século XXI, estarmos trabalhando com enormes volumes de papel. Seria impraticável e inviável, principalmente sob a ótica da eficiência e efetividade. Essas obrigações acessórias ajudam a minimizar os esforços despendidos e a melhorar os resultados almejados (AUDITOR 2).

Para ambos, as obrigações Sintegra e Sped Fiscal são de suma importância, pois nelas são declaradas toda a situação da empresa, o que facilita o meio da fiscalização, devido à informatização. 0 auditor 1 ainda nos mostra outros meios de conseguir auditar a empresa, o GIA ICMS. Além do MFD, todos servem para confrontar a veracidade das informações.

Ao serem perguntados se os meios são eficazes para evitar a sonegação, obtivemos as seguintes respostas:

A sonegação somente seria totalmente evitada se o Estado tomasse para si a tarefa de efetuar os registros fiscais dos sujeitos passivos, o que é inviável na prática. Como o próprio sujeito passivo é responsável pelos seus registros, como obrigação acessória, sempre haverá margem para a prática que vise a evitar o pagamento do tributo devido. (AUDITOR 1).

A legislação tributária impõe ao sujeito passivo a efetuação de registros que, normalmente, são suficientes para detectar o não pagamento de tributo devido, desde que essas informações estejam disponíveis. Nesse sentido, a legislação tem instituído novas obrigações acessórias com caráter eletrônico e elevado grau de automatização, como a Nota Fiscal Eletrônica e a Escrituração Fiscal Digital (SPED), o que reduz as possibilidades de sonegação, além da adoção pelo fisco de novos métodos eletrônicos de análise e cruzamento de dados em grande escala. (AUDITOR 1).

Não acredito que somente esses meios seriam eficazes. Deve-se somá-los aos outros processos de fiscalização para se ter um resultado melhor, sendo que, ainda assim, a sonegação não seria evitada por completo. A sonegação é algo mais relacionada à cultura e à vida social do que ao controle do Estado. Para evitá-la, teria que se mudar esses fatores (cultura e socialização), pelo menos em minha opinião. No meio desse processo e de mudança social e cultural está a figura do Auditor, logicamente sendo mais efetivo no controle. Acredito que seria um processo bem mais complexo para extinguir a sonegação da sociedade. (AUDITOR 2).

Observamos que as respostas obtidas tiveram opiniões diferentes. 0 auditor 1 nos diz que 0 sujeito passivo "tem" como evitar os pagamentos de tributos, uma vez que ele é quem registras as obrigações e esses meios de fiscalização não seriam suficientes para evitar a prática de sonegação. 0 auditor 2 diz que não somente esses meios seriam eficazes para se evitar a sonegação, já que ela está relacionada à cultura e à vida social.

A seguir, os auditores relataram o procedimento relativo às documentações a serem apresentadas, quando uma empresa está sendo auditada.

Isso depende do objetivo da fiscalização. Ela pode ser direcionada a operações específicas da empresa ou a todas as operações de determinados períodos. São solicitados os documentos que contenham as informações essenciais das operações de interesse da fiscalização, que, normalmente, são os livros fiscais e comerciais e os documentos fiscais, além da análise das declarações periódicas apresentadas pelo sujeito passivo. (AUDITOR 1). 
Temos uma relação de livros e documentos básicos para se iniciar uma auditoria. São vários livros fiscais, arquivos magnéticos e documentos de arrecadação necessários para que o Auditor possa trabalhar satisfatoriamente. Solicitamos esses documentos através de intimações e, sendo descumpridas, intimamos novamente aplicando as respectivas multas, sendo que, persistindo esses descumprimentos, fazemos, então, a denúncia ao Ministério Público, onde a fiscalização passa do meio administrativo para o meio judicial e criminal. Geralmente as empresas cumprem as intimações e, pelo menos nesse aspecto, não são maioria as que são denunciadas ao MP (AUDITOR 2).

Os auditores, ao fiscalizarem uma empresa, como já propriamente dito, necessitam de documentos fiscais que variam de acordo com a fiscalização, mas normalmente são os arquivos já enviados mensalmente, que têm a possibilidade de salvá-los, além dos livros e diversos outros documentos que irão ajudar no bom andamento da fiscalização.

Ao questionarmos sobre penalidades/multas para empresa, onde foi comprovada a prática da sonegação, obtivemos as seguintes respostas:

\begin{abstract}
"Sonegação" é uma expressão utilizada para descrever diversas condutas do sujeito passivo, que tem como objetivo evitar o recolhimento do tributo que seria devido, inclusive por meio de fraude, simulação, ocultação de informações ou embaraço à fiscalização. A depender das ações praticadas pelo sujeito passivo, ele estará sujeito à cobrança do tributo devido, com multas e juros de mora, além de ser apresentada ao Ministério Público representação de crime contra a ordem tributária (Lei 8.137/1990). (AUDITOR 1).
\end{abstract}

Esta é uma pergunta difícil de responder, uma vez que são extremamente diversas as formas de penalizar/multar as empresas que sonegam. Utilizamos um programa que faz esse trabalho para os Auditores e nós somente verificamos, após o programa capitular, se não houve nenhuma inconsistência com a Lei que trata da referida penalidade/multa. Ao falar sobre penalidade e multas, ambos nos informam sobre a Lei $8.137 / 1990$, que registra que: omitir; prestar declaração falsa; fraudar; falsificar; alterar nota fiscal entre outras são crimes contra a ordem tributária. (AUDITOR 2).

Há, ainda, um fato comum que é a retificação dos arquivos. Ao serem questionados sobre as penalidades para as empresas que retificam os arquivos, obtivemos as seguintes respostas:

A intimação é a comunicação, ao sujeito passivo, de que foi instaurado procedimento fiscal de verificação de suas atividades. Isso retira a possibilidade de apresentação de denúncia espontânea, de acordo com o art. 138 do Código Tributário Nacional. A partir daí o sujeito passivo estará sujeito a diversas multas por operação de declarações ou escrituração de livros ou SPED com dados omissos ou incorretos, além da cobrança das eventuais diferenças de imposto apurado a menor, acrescido de multas e juros de mora. (AUDITOR 1).

Quando a empresa retifica o arquivo e prova que aquelas novas informações são verdadeiramente corretas, as penalidades são mais brandas, uma vez que a empresa corrigiu o erro. Geralmente uma multa, nesses casos, quando não há dano irreparável para o Estado, varia de R\$ 500,00 a R\$ 2.000,00 (AUDITOR 2).

Ao questionar sobre essa questão da retificação, notamos que os fiscais afirmaram que multas e juros serão cobrados de acordo com o art. 138, porém se alteradas para a informação correta, as penalidades são mais brandas, conforme afirma o auditor 2 . Ao serem questionados sobre o tempo médio de auditoria dispensado em uma empresa, as respostas foram:

A legislação tributária estadual determina um prazo de 60 dias para a conclusão do procedimento fiscal, podendo esse prazo ser prorrogando, caso necessário. A depender da complexidade da verificação e da cooperação do sujeito passivo no atendimento às intimações, o procedimento fiscal pode durar de poucas semanas a alguns meses, terminado em média por volta dos 60 dias de prazo inicial. (AUDITOR 1).

Geralmente uma auditoria completa dura 6 meses, isso com todas as intimações sendo cumpridas dentro do prazo e com maior número de arquivos informatizados para se trabalhar. No entanto, não há uma regra, podendo durar menos do que isso ou até mais. (AUDITOR 2). 
O tempo para as análises das documentações varia de acordo com a finalidade da auditoria. 0 auditor 1 nos informou que dura cerca de 60 dias, porém o auditor 2 diz que a regra pode mudar, podendo-se estender para mais ou menos que o tempo estipulado.

Solicitou-se aos auditores que relatassem uma experiência envolvendo a prática da sonegação. As seguintes respostas foram obtidas:

\begin{abstract}
A forma mais comum de sonegação é a falta de emissão de documentos fiscais, como notas fiscais ou cupom fiscal, nas operações de venda de mercadorias no comércio varejista, situação que ocorre omissão de receita e ocultação de operação com débito do ICMS. Lamentavelmente é muito comum, embora os prejuízos aos cofres públicos tenham sido reduzidos pelo regime de recolhimento do ICMS em substituição tributária (AUDITOR 1).
\end{abstract}

Muitas empresas vendem mercadorias sem emitir as respectivas notas fiscais. Isso ainda é muito comum, infelizmente. Já atuei em alguns casos concretos nesse sentido e a multa é bem pesada para essa infração, já que a empresa geralmente sonega por um longo período de tempo e quando o Estado chega já tem muito débito acumulado (AUDITOR 2).

Conforme a resposta de ambos, suas experiências como auditores estão envolvidas em omissão de notas fiscais, cupom fiscal, que, na maioria dos casos, acontece no comércio varejista. Posteriormente os auditores falaram sobre quantas empresas são fiscalizadas por ano e, também, sobre as que praticam sonegação.

\begin{abstract}
Isso depende muito da complexidade das verificações, além da quantidade de trabalho interno da inspetoria, como plantões fiscais e análise de processos. Em média, creio que os fiscais trabalhem com 60 a 90 fiscalizações por ano, com diversos graus de complexidade. A legislação tributária é complexa e é difícil ao sujeito passivo cumpri-la com total exatidão. Quanto à sonegação propriamente dita, é difícil estipular uma proporção, por uma série de motivos. Primeiramente, as empresas que sofrem fiscalização são selecionadas por um órgão central da Subsecretaria da Receita Estadual, mediante critérios que visam a identificar empresas com alta probabilidade de incorreção nas apurações do ICMS. Além disso, a depender do tipo de atividade, ela parece ser mais frequente, como no supracitado caso da falta de emissão de notas fiscais e cupons fiscais no comércio varejista. (AUDITOR 1).
\end{abstract}

Umas 20 empresas por ano, mas isso depende do tipo de fiscalização. Tem fiscalizações que são direcionadas (mais fáceis) e outras fiscalizações são completas (mais complexas). A sonegação envolve o dolo e, geralmente nas fiscalizações, se depara muito com o erro (que, em tese não caracteriza a sonegação). Excetuando-se o caso da não emissão de nota fiscal tratado na questão anterior, digamos que uns $10 \%$ das empresas fiscalizadas estariam praticando a sonegação, ou seja, dolosamente e voluntariamente, utilizando de práticas ilícitas no campo tributário. Mas isso é só uma estimativa pessoal, não dá para se ter um número mais exato e confiável sem antes realizar um grande trabalho de apuração estatístico desenvolvido por profissionais qualificados. (AUDITOR 2).

Cerca de 20 a 90 empresas são fiscalizadas ao ano, pois algumas fiscalizações são mais fáceis e outras, mais complexas. Nas fiscalizações, geralmente, se depara com erros que nem sempre é um caso de sonegação. Cerca de $10 \%$ das empresas fiscalizadas estão praticando a sonegação, que é mais frequente com a falta de emissão de notas fiscais e cupons fiscais no comércio varejista.

\title{
6 CONSIDERAÇÕES FINAIS
}

Com este artigo, tivemos um olhar abrangente de auditoria externa. Percebeu-se que seu surgimento se deu com o objetivo de analisar e verificar os registros e informações contábeis de uma empresa. Olhar minunciosamente todos os documentos que circulam dentro de uma entidade a fim de detectar fraudes e a sonegação é seu principal papel.

No decorrer do artigo, vimos que a sonegação, no Brasil, ainda é muito presente, conforme mostrou o Instituto Brasileiro de Planejamento Tributário. Existem diversas maneiras para se praticar a sonegação, entretanto o Governo Federal, através da Receita, vem elaborando métodos eficazes para se evitar a prática. 
Conforme vimos na pesquisa de campo, existe um conjunto de obrigações a serem entregues mensalmente à Receita: o Sintegra, que tem o objetivo de mostrar a totalidade das operações de compra e venda, aquisições e prestações, internas e interestaduais que a empresa tenha praticado; o Sped Fiscal, que possui em seu arquivo txt um conjunto de escriturações de documentos fiscais, que tem por objetivo verificar todos os registros de apuração de impostos referentes às operações no decorrer daquele mês. Esses meios, para terem mais eficácia, dependem, também, de um conjunto de documentos, para que haja o confrontamento das informações.

O trabalho investigativo sobre a sonegação e auditoria externa não se encerra neste artigo. Novas pesquisas deverão ser desenvolvidas para um melhor aprofundamento e complementação do assunto proposto, visto que o governo, através da Receita Federal, vem sempre elaborando métodos específicos de auditoria para se evitar a sonegação. A partir de julho de 2014, o Sintegra não é mais obrigatório, de acordo com o protocolo 177/2013:

\footnotetext{
Cláusula terceira. 0 estabelecimento de contribuinte obrigado à EFD será dispensado de entregar os arquivos estabelecidos no Convênio ICMS 57/95 e no inciso I da cláusula décima terceira do Convênio ICMS 81/93, a partir de $1^{\circ}$ de janeiro de 2014.
}

Porém, acreditamos que será substituída por outra obrigação, possibilitando novas pesquisas exploratórias sobre o assunto. 


\section{REFERÊNCIAS}

ALMEIDA, Marcelo Cavalcanti. Auditoria: um curso moderno e completo. São Paulo: Atlas, 2012.

ATTIE, William, Auditoria conceitos e aplicações. 6. ed. São Paulo: Atlas, 2011.

CAMARGO, Roberto, Infração Tributável e Penal, Nota Fiscal Calçada,08/03/2008 Disponível em: <http:robertocamergo.typedad.com/educacaotributaria/2008/08/nota-fiscal-cal.html>. Acesso em: 10 dez. 2013.

CREPALDI, Silvio Aparecido, Auditoria contábil. 5. ed. São Paulo: Atlas, 2009.

CUNHA, Jacqueline V. Alves, EDGARD, Bruno Cornachione Jr. Fraudes e tecnologia da informação: análise das influências em sistemas contábeis e empresariais. Revista Brasileira de Contabilidade $\mathrm{n}^{\circ} 144, \mathrm{CFC}, 2003$.

IBPT: Instituto Brasileiro de Planejamento e Tributação. Estudo sobre sonegação fiscal das empresas brasileiras. Disponível em: <http://www.ibpt.com.br/img/uploads/novelty/estudo/49/ EstudoVeQuedaNaSonegacaoFiscalDasEmpresasBrasileiras.pdf>. Acesso em: 10 jun 2016.

LEI No 8.137/1990 Disponível em: <http://www.fiscosoft.com.br/g/9h/lei-n-8137-de-27121990>. Acesso em:10 dez. 2013.

MARTINS, Ives Gandra da Silva. Curso de direito tributário. 3. ed. Belém: CEJUP; Centro de Extensão Universitária, 1994.

MELLO, Fábio Bandeira de, 0 que pode acontecer com quem sonega impostos, 13/01/2010 Disponível em: $<$ http://www.administradores.com.br/informe-se/informativo/o-que-pode-acontecer-com-quemsonega-impostos/29312/>. Acesso em: $10 \mathrm{dez} .2013$.

PINHEIRO, Geraldo José; CUNHA, Luís Roberto. A importância da auditoria na detecção de fraudes. Cont. Vista \& Ver. Belo Horizonte, vol $14 n^{\circ}$ 1, abr, 2003.

SANTOS, A. Metodologia do trabalho científico. São Paulo: Atlas, 2001.

SEFAZ-ES - SECRETARIA DO ESTADO DA FAZENDA DO ESPIRITO SANTO. Sintegra. Disponível em: $<$ http://www.sefaz.es.gov.br/sintegra/inicio.asp>. Acesso em: 15 jun. 2016.

SOUZA, Orlando Oliveira de, Meia Nota, 13/06/2009 Disponível em: <http://forum.jus.uol.com.br/138940>. Acesso em: 10 dez. 2013.

STIGLITZ, Joseph E. A Globalização: como pode dar certo. São Paulo: Companhia das Letras, 2007. 